\title{
An Optimal Combinational Coalition Formation Based On Genetic Algorithm
}

\author{
Hao Li ${ }^{1}$ Jinhu Jiang ${ }^{1}$ \\ ${ }^{1}$ School of Management, Xi'an Jiaotong University, P. R. China
}

\begin{abstract}
In electronic commerce, the purchasing power of an individual buyer is limited. Sellers' discount policies are often based on the cost of a single transaction. A profitable purchasing strategy for buyers is to form buyer coalition in order to lower their cost. The key problem is how to form combinational coalitions among buyers in order to minimize the total cost of all buyers. In this paper, we formally analyze the problem and solve it by using the genetic algorithm. Our method can optimally allocate buyers in an efficient time. The experimental results show that the algorithm is feasible and effective.
\end{abstract}

Keywords: Combinational Coalition, Genetic Algorithm, Electronic Commerce

\section{Introduction}

With the development and commercial application of information technology, electronic commerce has become a popular channel for transactions between buyers and sellers. Buyers can access information from more sellers on the Internet. Meanwhile, sellers can provide their goods to more buyers without geographical or temporal limitations. For the purpose of promotion, sellers often offer different discount rates based on the cost of one transaction. Correspondingly, for buyers one profitable purchasing strategy is to form buyer coalitions in order to increase the cost of their transaction. In this way, buyers can obtain lower prices without buying more than their real demand.

One kind of buyer coalition is called the combinational coalition when sellers offer a variety of goods which is needed by different buyers [1]. The problem is to find an optimal combinational coalition structure, which is an NP-hard problem [2]. Therefore, searching for an optimal buyer distribution by an exhaustive search is not practical because it takes too much time. A genetic algorithm (GA) is a heuristic search scheme based on a model of Darwininian evolution [3]. It can calculate optimal solutions or semi-optimal solutions in real time [4]. Thus, it is feasible to solve the problem based on GA.

In this paper, we consider a coalition formation problem in which a group of buyers are shopping from a certain group of sellers for a variety of goods. The buyers have different shopping lists. Different sellers offer different retail prices and different discount policies based on the total cost of all goods sold in one transaction. Under this circumstance, we solve the optimal combinational coalition formation problem using a method based on GA.

Some researchers have discussed coalition formation problem in different context. Sen et al. [5] propose a GA-based search algorithm for optimal coalition structures. They use the Order Based Genetic Algorithm (OBGA). Although the OBGA has no performance guarantee, they insist that it surpasses existing deterministic algorithms. Yamamoto and Sycara [6] propose a buyer coalition for- 
mation scheme GroupBuyAuction, where buyers form a group based on a category of items. Tsvetovat et al. [7] use economic incentives to create buying group of buyers who procure goods at a volume discount. Li and Sycara [1] combine coalition formation with combinatorial auction, where each buyer places a bid on items with reservation prices. Hyodo et al. [8] optimally allocate buyers to several group buying sites which sell substitute goods and charge prices based on the number of items sold in each transaction. Their approach is based on a genetic algorithm. Buyers with multi-attribute preferences are integrated into a coalition in the system proposed by Matsuo et al. [9]. Boongasame et al. [10] present an algorithm for forming a buyer coalition with bundles of items, which refers to selling more than one goods together in a package at a price which is lower than the sum of the independent prices [11]. On the basis of existing study, we analyze the more popular purchasing pattern in the market - combinational purchasing, in which buyers purchase a variety of heterogeneous goods from different sellers who offer different discount policies based on the total cost of one transaction.

The rest of this paper is organized as follows. Section 2 gives a formal definition of the combinational purchasing problem we study in this paper. Section 3 describes the method to solving this problem based on GA. In Section 4, we show an experiment and analyze the results. Finally, Section 5 gives the conclusions and future work.

\section{Problem Formalization}

\subsection{Formal Problem Definition}

Let $G=\left\{g_{1}, g_{2}, \ldots, g_{l}\right\}$ denote the collection of goods items. There is a group of buyers $B=\left\{b_{1}, b_{2}, \ldots, b_{m}\right\}$. Each of them has a shopping list denoted by vector $Q_{i}=\left(q_{i 1}, q_{i 2}, \ldots, q_{i l}\right)$, where $q_{i k}$ refers to the quantity of each item $g_{k}$ buyer $b_{i}$ needs to buy $(i=1,2, \ldots, m ; k=1,2, \ldots, l)$. There is a set of sellers $S=\left\{s_{1}, s_{2}, \ldots, s_{n}\right\}$ who can supply all $l$ kinds of goods. For each seller, there is a retail price vector $P_{j}=\left(p_{j 1}, p_{j 2}, \ldots, p_{j l}\right)$, where $p_{j k}$ refers to the price of each item $g_{k}$ seller $s_{j}$ charges $(j=1,2, \ldots, n ; k=1,2, \ldots, l)$. Also each seller $s_{j}(j=1,2, \ldots, n)$ has its own discount rate function $f_{j}(c): R^{+} \rightarrow[0,1)$, which is the discount rate a buyer obtains when the cost of his purchase from seller $s_{j}$ is $c$. That is, the buyer actually needs to pay $c\left[1-f_{j}(c)\right]$ for the transaction.

The objective of this problem is to minimize the total cost of all buyers' purchase.

\subsection{Problem Analysis}

The discount rate is defined as the rate of the discount to the corresponding cost. Table 1 shows an example of the seller's discount policy. If a transaction between a buyer and this seller costs $\$ 650$, this buyer will obtain $10 \%$ discount. Thus he just needs to pay $\$ 585$ to get the desired goods. Generally, the more the transaction costs, the higher discount rate the buyer will obtain. The purchasing power of an individual buyer is usually limited, which makes him not to obtain high discount rate. Therefore, it is valuable to cooperate with other buyers and to form buyer coalition for purchase. Every coalition member will benefit from cooperation. 


\begin{tabular}{l|l}
\hline the cost in one transaction $(\$)$ & $\begin{array}{l}\text { discount } \\
\text { rate }\end{array}$ \\
\hline $500-800$ (not including 800$)$ & 0.1 \\
\hline $\begin{array}{l}800-1000 \text { (not including } \\
1000)\end{array}$ & 0.2 \\
\hline 1000 and more & 0.3 \\
\hline
\end{tabular}

Table 1: An example of a discount rate table.

In this paper, a coalition is a subset of the buyer set. Members of a coalition will contribute at least a portion of their total cost of buying all goods that they need. Because each buyer needs to buy multiple goods, we allow a buyer to join multiple coalitions simultaneously by contributing some of his purchase items. A coalition structure is a partition of all goods that all buyers need to buy, rather than a partition of buyers. The solution to the problem has to clearly show the coalitions and coalition structure. Let $T=\left\{t_{\text {ad }} \mid a=1,2, \ldots, m ; d=1,2, \ldots, l\right\}$ denote the solution, where $t_{a d} \in S$ refers to that buyer $b_{a}$ should buy item $g_{d}$ from seller $t_{a d}$.

There are numerous sellers in the market. Although buyers can easily get information about retail prices and discount policies on the Internet, it is difficult to obtain complete information about all sellers and then select the optimal one, especially when buyers wish to buy multiple goods. For an individual buyer, it is complicated to find his optimal selection and the lowest cost. Hence, buyers can choose to form coalitions to lower their cost. In this paper, we focus on the total cost of all buyers rather than that of each buyer. If seller $S_{i}$ doesn't offer any discount policy, then for all $t_{a d}=s_{i}$, the total cost of purchase from this seller is $c_{i}=\sum_{a=1}^{m} \sum_{d=1}^{l} p_{i d} * q_{a d}$. The objective of the problem is represented as follows.

$$
\min \sum_{i=1}^{n} c_{i}\left[1-f_{i}\left(c_{i}\right)\right]
$$

Eventually, the real cost of each buyer is

$$
\sum_{d=1}^{l} p_{t_{a d}, d} * q_{a d} *\left[1-f_{t_{a d}}\left(c_{t_{a d}}\right)\right] \quad(a=1,2, \ldots, m)
$$

\subsection{Assumptions}

- Buyers believe that their cost will be lower after joining combinational coalition. But they do not consider the exact gain.

- Buyers do not bargain with sellers.

- The discount function of each seller is fixed.

- Each seller can sell all kinds of goods without stock limitation.

- Each buyer can join multiple coalitions at the same time if necessary. Namely, in order to obtain higher discount rate, buyers can partition their own shopping lists and purchase them through different transactions.

- Since the discount rate is a function of the total cost of all goods sold from one seller in one transaction, we can treat multiple same goods items as multiple different items. Without losing generality, we assume in each $Q_{i}, q_{i j}$ is equal to 1 or 0 .

\section{Coalition Formation Algorithm Based on GA}

\subsection{Coding}


We represent the problem with genes. In this algorithm, genes are coded with integers in the interval $[1, n]$, where $n$ is the number of sellers. The length of an indi vidual is $m^{*} l$, which represents the number of genes in an individual. The first to the $l$-th genes correspond to the items in the shopping list $Q_{1}$ of the buyer $b_{1}$. The $l+1$-th to the $2 l$-th genes correspond to the items in the shopping list $Q_{2}$ of the buyer $b_{2}$. The rest can be deduced by analogy. The integer of the gene indicates the buyer should buy the item from which seller.

\subsection{Fitness function}

The fitness function is the one you want to minimize or maximize. In our combinational coalition formation problem, we set the objective function (1) to be the fitness function of the algorithm.

\subsection{Selection}

We apply both the deterministic sampling and the elitist model. The deterministic sampling guarantees that the individuals with greater fitness values must be chosen. The elitist model makes the rare elite to directly survive to the next generation.

\subsection{Crossover}

Crossover is a very characteristic operation to create children. It determines the global searching performance of the GA. In our method, the uniform crossover function is used, which creates a random binary vector and selects the genes where the vector is a 1 from the first parent, and the genes where the vector is a 0 from the second parent, and combines the genes to form the child.

\subsection{Mutation}

enables GA to search a broader space. The uniform mutation is applied in our method. It is a two-step process. First, the algorithm selects a fraction of the vector entries of an individual for mutation, where each entry has a probability rate of being mutated. In the second step, the algorithm replaces each selected entry by a random number selected uniformly from the range for that entry.

\section{Experiment}

In this section, we conducted an experiment to show the effectiveness of our method. The experimental environment was Matlab 7.0.0 and executed on a Pentium(R) $4 / 2.40 \mathrm{GHz} / 512 \mathrm{MB}$ computer running Windows XP.

\begin{tabular}{l|l|l|l|l|l}
\hline & \multicolumn{3}{|l}{ Goods } \\
\cline { 2 - 6 } & A & B & C & D & E \\
\hline Buyer 1 & 1 & 1 & 1 & 1 & 1 \\
\hline Buyer 2 & 1 & 1 & 0 & 0 & 1 \\
\hline Buyer 3 & 0 & 1 & 0 & 1 & 0 \\
\hline Buyer 4 & 1 & 1 & 1 & 1 & 1 \\
\hline Buyer 5 & 0 & 1 & 1 & 1 & 0 \\
\hline Buyer 6 & 1 & 1 & 0 & 1 & 1 \\
\hline Buyer 7 & 1 & 0 & 1 & 1 & 0 \\
\hline Buyer 8 & 0 & 0 & 1 & 0 & 0 \\
\hline Buyer 9 & 0 & 0 & 1 & 1 & 1 \\
\hline
\end{tabular}

Table 2: Buyers' shopping lists.

\begin{tabular}{l|l|l|l|l|l}
\hline \multirow{2}{*}{} & \multicolumn{4}{|l}{ Goods } \\
\cline { 2 - 6 } & A & B & C & D & E \\
\hline Seller 1 & 120 & 210 & 75 & 145 & 350 \\
\hline Seller 2 & 135 & 200 & 50 & 160 & 340 \\
\hline Seller 3 & 130 & 200 & 55 & 150 & 355 \\
\hline
\end{tabular}

Table 3: Retail prices(\$) of goods. 


\begin{tabular}{l|l}
\hline the cost in one transaction $(\$)$ & $\begin{array}{l}\text { discount } \\
\text { rate }\end{array}$ \\
\hline $500-800$ (not including 800$)$ & 0.1 \\
\hline $800-1000$ (not including 1000) & 0.2 \\
\hline 1000 and more & 0.25 \\
\hline
\end{tabular}

Table 5: Discount rates of seller 2.

\begin{tabular}{l|l}
\hline the cost in one transaction $(\$)$ & discount rate \\
\hline $600-900$ (not including 900) & 0.12 \\
\hline $\begin{array}{l}900-1200 \text { (not including } \\
1200)\end{array}$ & 0.22 \\
\hline 1200 and more & 0.3 \\
\hline
\end{tabular}

Table 4: Discount rates of seller 1.

The problem to be solved in the experiment is shown in Table 2 with the shopping lists of nine buyers. They have diverse demand to five different goods. The " 0 " in the table means that buyers have no requests to buy the specific goods. The different retail prices set by three seller are shown in Table 3. Sellers' different discount policies are shown in Table 4, 5 and 6. Our method's parameters include a population size of 45 , a generation count of 100 , a crossover rate of 0.95 , and a mutation rate of 0.0005 . If there is no improvement in the best fitness value for 50 generations or for 20 seconds, the algorithm will stop. The initial population was randomly created with a uniform distribution.

\begin{tabular}{l|l}
\hline the cost in one transaction $(\$)$ & discount rate \\
\hline $\begin{array}{l}600-1000 \text { (not including } \\
1000)\end{array}$ & 0.1 \\
\hline 1000 and more & 0.2 \\
\hline
\end{tabular}

Table 6: Discount rates of seller 3.

Table 7 shows the optimal solution found by using our method. The first " 1 " means that buyer 1 should purchase good A from seller 1. The last " 3 " means that buyer 9 should purchase good E from seller 3. The " 0 " in the table corresponds to the same " 0 " in the shopping lists. In this solution, the total cost of all nine buyers is $\$ 4012.3$. By joining the combinational coalition, buyers obtain a higher discount rate than they may get when purchasing separately. Take buyer 8 who only demand good $\mathrm{C}$ for example. This buyer can minimize his cost by purchasing from seller 2 when he is alone. But if he cooperates with other eight buyers to form combinational coalition, his cost will be lowered from $\$ 50$ to $\$ 44$ by obtaining $20 \%$ discount from seller 3 .

\begin{tabular}{l|l|l|l|l|l}
\hline \multirow{2}{*}{} & \multicolumn{5}{|c}{ Goods } \\
\cline { 2 - 6 } & A & B & C & D & E \\
\hline Buyer 1 & 1 & 1 & 3 & 3 & 1 \\
\hline Buyer 2 & 1 & 1 & 0 & 0 & 1 \\
\hline Buyer 3 & 0 & 3 & 0 & 3 & 0 \\
\hline Buyer 4 & 1 & 3 & 3 & 3 & 3 \\
\hline Buyer 5 & 0 & 2 & 2 & 3 & 0 \\
\hline Buyer 6 & 3 & 1 & 0 & 2 & 3 \\
\hline Buyer 7 & 1 & 0 & 3 & 1 & 0 \\
\hline Buyer 8 & 0 & 0 & 3 & 0 & 0 \\
\hline Buyer 9 & 0 & 0 & 3 & 2 & 3 \\
\hline
\end{tabular}

Table 7: Results.

Figure 1 shows that GA can find an optimal solution in less than 20 generations. It is feasible to adjust the population size and other parameters in order to find an appropriate solution when the problem becomes more complicated.

\section{Conclusions and Future Work}

In this paper, we analyze the emerging buyer purchasing strategy - buyer coalition formation with formal mathematical description. Sellers' discount policies are often based on the cost of one transaction.Because the purchasing power of an individual is limited, different buyers can cooperate in buyer coalition to lower their cost. To solve the important coalition 
formation problem, we proposed a method based on GA. The notable advantage of using GA is that we can find an appropriate solution in an efficient time. The experiment demonstrated that our method is feasible and effective to find an optimal solution.

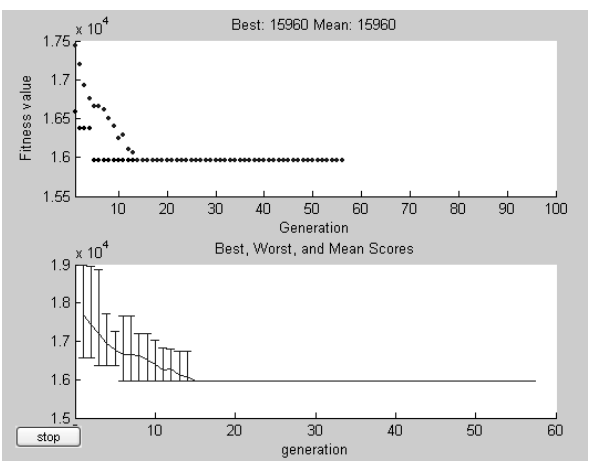

Fig. 1: Results of GA.

This paper is only the beginning of our research. There are several conditions we need to seriously discuss in the future. First, as more buyers participate in the combinational coalitions, the constraint of seller's stock of goods shoud be considered. Second, some buyers purchase with a reservation price. When the price of the goods is higher than the reservation price, the buyer does not purchase the goods. In this case, the objective function should be reformulated to meet the requirement. Third, it is useful to consider the actual bargain power of buyers, which is omitted in this study. Finally, improving the algorithm to enhance the efficiency of the method is very important.

\section{References}

[1] C. Li and K. Sycara, Algorithm for combinatorial coalition formation and payoff division in an electronic marketplace. In proceedings of the First International Joint Conference on Autonomous Agents and Multi-agent
Systems (AAMAS), pp. 120-127, Bologne, Italia, 2002.

[2] Y. Chang, C. Li and J. R. Smith, Searching dynamically bundled goods with pairwise relations. In proceedings of ACM Electronic Commerce, pp. 135-143, San Diego, 2003.

[3] TC. Yang and H Lai, Comparison of product bundling strategies different online shopping behaviors, Electronic Commerce Research and Applications, Vol. 5, Issue 4, pp. 295-304, 2006.

[4] D. E. Goldberg, editor. Genetic Algorithms in Search Optimization and Machine Learning, Addison-wesley, New York, 1989.

[5] S. Sen and S. Dutta, Searching for optimal coalition structures. In proceedings of the Fourth International Conference on Multiagent Systems, pp. 286-292, Boston, 2000.

[6] J. Yamamoto and K. Sycara, A Stable and Efficient Buyer Coalition Formation Scheme for E-Marketplaces. In proceedings of the 5th International Conference on Autonomous Agents, pp. 576-583, Monttreal, Quebec, Canada, 2001.

[7] M. Tsvetovat, K. P. Sycara, Y. Chen and J. Ying, Customer Coalitions in Electronic Markets. In Lecture Notes in Computer Science 2003, pp. 121138, Springer, 2001.

[8] M. Hyodo, T. Matsuo and T. Ito, An Optimal Coalition Formation among Buyer Agents Based on a Genetic Algorithm. In P. W .H. Chung, C. J. Hinde and M. Ali, editors, IEA/AIE, LNAI 2718, pp. 759-767, 2003.

[9] T. Matsuo, T. Ito and T. Shintani, A Buyers Integration Support System in Group Buying. In proceedings of the IEEE international Conference on ECommerce Technology, pp. 111-118, 2004.

[10] L. Boongasame, H. Leung, V. Boonjing and D. K. W. Chiu, Form- 
ing Buyer Coalitions with Bundles of Items. In A. Hakansson et al., editors, Lecture Notes in Computer Science 5559, pp. 714-723, Springer, 2009.

[11] U. Gurler, S. Oztop and A. Sen, Optimal Bundle Formation and Pric- ing of two products with limited stock, International Journal of Production Economics, Vol. 118, Issue 2, pp. 442-462, 2009. 